\title{
PERBEDAAN NILAI ( VALUE) DAN MAKNA (MEANING) BUDAYA PERMAINAN EGRANG DI EMPAT NEGARA
}

\author{
Kendall Malik \\ Program Studi Desain Komunikasi Visual Fakultas Seni Rupa dan Desain \\ Institut Seni Indonesia Padangpanjang \\ Jl. Bahder Johan, Guguak Malintang, Padangpanjang, Kota Padangpanjang, 27126. \\ Sumatera Barat. Indonesia \\ Email: kendall.malik@gmail.com
}

\begin{abstract}
Abstrak
Mainan egrang merupakan mainan tradisional yang sudah dimainkan oleh masyarakat zaman dulu. Budaya bermain disetiap daerah, suku/ras, budaya dan tradisional merupakan suatu kegiatan yang didasari oleh latar belakang sejarah, budaya dari nenek moyang dan leluhur tersebut. Hal ini kegiatankegiatan bermain tersebut melahirkan suatu makna dan arti budaya itu sendiri. Suatu budaya bermain itu dapat menggambarkan, mencerminkan dan mengartikan karakter suatu daerah/negara tertentu. Permainan egrang yang dimiliki oleh negara-negara lain ternyata menyimpan latar belakang sejarah dan budaya yang bermakna sehingga permainan tersebut menjadi salah satu pertunjukan yang penting dalam suatu acara atau even. Permainan Egrang dilakukan oleh muda mudi, umumnya anak laki - laki mulai yang umur 10-25 tahun dan hanya sebagian kecil anak perempuan. Permaianan ini merupakan permainan ketangkasan. Nilai budaya yang terkandung dalam permainan ini adalah kerja keras, keuletan, keseimbangan dan sportivitas. Hal ini menjadi mainan menghibur diri yang menarik dan mainan yang berusur ketangkasan. Mainan ini cenderung menarik perhatian karena ketinggiannya yang menbuat atraksi-atraksi di arak-arakan pada acara - acara tahunan.
\end{abstract}

Kata Kunci: egrang, permainan, makna, budaya.

\begin{abstract}
The Stilts is traditional toys that played in the past. The Games traditional are every region/ras, district, culture and traditional have stories and ancestors culture behind it. The games have borned the culture meaning by own. The game traditional can describe to district characteristic and culture. From another countries, the Stilts game have history background and culture meaning that games become the main performence of the event. On the other side, the stilts game are played by young male people between 10 and 25 years old and female play a little. This game is agility games. The Cultural value in this game contents hard work, balance, tenacity and sporty. This game is attractive game that contens agility games. In addition, the game is attractive by audience because the users look tall than the others, and the event look anttractive.
\end{abstract}

Keywords: the stilts, games, meaning, culture.

\section{PENDAHULUAN}

Permainan tradisional merupakan salah satu bagian dari suatu tradisi yang menjadi salahsatu pengaruh dari kebudayaan dan adat yang dibawa oleh nenek moyang atau leluhur-leluhur. Namun disetiap daerah atau negara memiliki permainan tradisionalnya masing-masing, walaupun ada beberapa daerah atau negara yang permainan tradisionalnya sama namun dalam penamaannya dan permainannya (pola bermain) tersebut berbeda.

Mainan egrang merupakan mainan tradisional yang sudah dimainkan oleh masyarakat zaman dulu. Selain sarana transportasi, egrang juga berfungsi sebagai alas kaki untuk pergi ke Mesjid, karena zaman dulu orang belum menggunakan sendal. Di samping itu engrang ini juga dimainkan dalam bentuk pertandingan dan pertunjukan dari suatu daerah atau di negara tertentu dimana permainan tersebut memiliki makna yang tersendiri yang diturunkan secara turun temurun oleh nenek moyang dari satu suku atau budaya.

Budaya bermain disetiap daerah, suku/ras, budaya dan tradisional merupakan suatu kegiatan yang didasari oleh latar belakang sejarah, budaya dari nenek moyang dan leluhur tersebut. Hal ini kegiatankegiatan bermain tersebut melahirkan suatu makna dan arti budaya itu sendiri. Suatu budaya bermain itu dapat menggambarkan, mencerminkan dan mengartikan karakter suatu daerah/negara tertentu. 


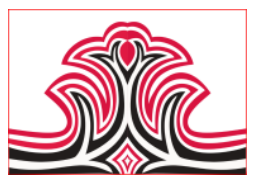

Masyarakat sudah tidak lagi mermainkan mainan egrang, tapi umumnya masyarakat lebih memainkan egrang diwaktu acara - acara kebesaran atau helaran lainnya. Dilingkungan masyarakat sekarang lebih mengikuti budaya dari luar tapi ironisnya masyarakat pedesaan sudah dipengaruhi oleh budaya yang berunsur teknologi yang terdapat dipermainan anak anak sekarang. Ini suatu kekhawatiran bagi sebagian negara yang berbudaya karena cepat atau lambat budaya tersebut akan terkikis secara berlahan - lahan sehingga habis dan menjadi punah.

Tulisan ini membahas makna permainan engrang dari empat negara yang sudah penulis pilih sesuai dengan latarbelakang budaya yang berbeda-beda. Negaranegara tersebut meliputi; Indonesia, Belgia, Mexico dan Nigeria. Permainan egrang yang dimiliki oleh negara-negara tersebut ternyata menyimpan latar belakang sejarah dan budaya yang bermakna sehingga permainan tersebut menjadi salah satu pertunjukan yang penting dalam suatu acara atau even.

\section{KAJIAN TEORI}

Kajian teori dalam tulisan ini adalah kajian konsep budaya dalam pertunjukan tradisional biasanya diikuti oleh suku secara keseluruhan yang diaplikasikan pada setiap daerah.(Manggis, 1971). Konsep berfikir terdapat dalam beberapa budaya yang diaplikasikan pada baik didaerah-daerah maupun dinegara-negara. Begitupun budaya bermain yaitu permainan engrang yang dulunya hanya sebagai permainan namun sekarang permainan itu bergeser dalam sebuah pertunjukan tradisional yang memiliki cirikhas tersendiri dan even tahunan yang diperingati oleh suatu suku yang sudah disepakati dari dulu oleh nenek moyang suku tersebut. Hal ini melahirkan nilai dan makna yang berbeda-beda dari hasil latarbelakang suku dan budaya, meliputi : negara Nigeria, Mexico, Belgia dan Indonesia.

Menurut Alo Liliweri (2004) didalam bukunya menyatakan bahwa budaya berubah dikarenakan manusia seperti: pemikiran, secara fisik, psikologis dan kebiasaan sebuah pertunjukan. Disamping itu juga budaya berubah karena perkembangan manusia itu sendiri, secara social dan budaya. Dengan demikian konsep budaya, nilai dan makna dari sebuah budaya bermain dipengaruhi oleh empat factor diatas yang menjadi perkembangan pemikiran manusia yang kian maju dan berjalannya waktu menjadikan permainan itu menjadi pertunjukan yang iconic disetiap empat negara tersebut. Hal ini dapat mencerminkan sistem sosial dan budaya yang dimiliki oleh masyarakat itu
Gorga Jurnal Seni Rupa

Volume 08 Nomor 01 Januari-Juni 2019

p-ISSN: 2301-5942 | e-ISSN: 2580-2380

sendiri. Di samping itu, secara psikologis permainan ini telah dikategorikan permainan ketangkasan yang dapat membetuk karakter yang kuat, disiplin, dan teguh pendirian.

\section{METODE PENELITIAN}

Penelitian ini dilakukan melalui metode kualitatif dengan pendekatan etnografi yang menekankan suatu metode penelitian ilmu sosial. Penelitian ini sangat menekankan ketertutupan, pengalaman pribadi dan partisipasi yang mungkin, tidak hanya pengamatan oleh penelitian yang terlatih dalam seni etnografi. Fokus penelitian ini meliputi studi intensif budaya, historis, observasi dan library research (rujukan perpustakaan).

Penelitian dalam mainan engrang ini dapat didekati dari titik pandang preservasi seni dan kebudayaan, dan lebih sebagai suatu usaha deskriptif daripada usaha analitis. Penelitian ini penulis fokuskan juga pada aspek budaya dan tradisional masyarakat di empat negara, dari nilai dan makna kehidupan sosial dan pandangan tentang berbagai kegiatan masyarakat.

\section{HASIL DAN PEMBAHASAN}

\section{Hasil}

Hasil penelitian ini memusatkan kajian pada makna permainan Egrang sebagai media mainan tradisional yang dikaji dari empat negara yang berbeda yaitu Indonesia, Belgia, Mexico dan Nigeria. Permainan egrang ini memiliki latar belakang dan sejarah dimana mainan yang berunsur ketangkasan dan sporifitas.

\section{1).Latar Belakang Mainan Egrang sebagai Media Mainan Tradisional}

Egrang merupakan lanjutan dari permainan kelom batok karena memakai media bambu dan lebih tinggi dari kelom batok. Egrang biasanya untuk anak yang lebih besar dan lebih berani terhadap ketinggian. (Lihat Gambar 1). Kelom batok memakai batok kelapa sebagai medianya. Mainan ini mengeluarkan suara pada saat dipakai jalan. Bedanya, egrang menggunakan material bambu sedangkan kelom batok menggunakan batok kelapa yang dibelah dan tali terbuat dari pohon. 


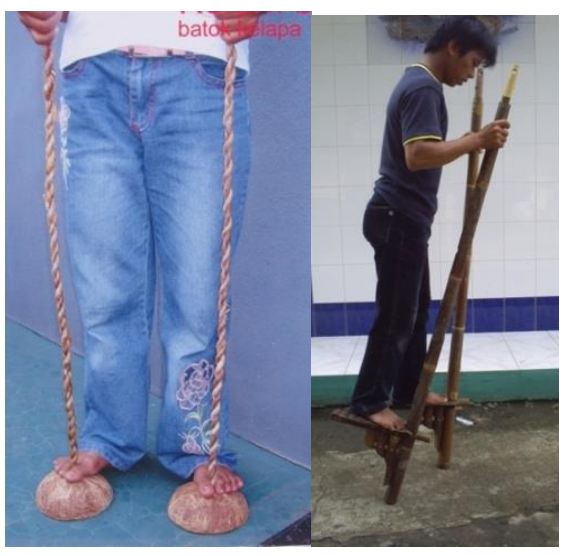

Gambar 1. Kelom Batok dan Egrang (Sumber: Kendall Malik dan Muhammad Zaini Alif, 2007)

Istilah Egrang disebut di Tanah Sunda adalah Jajangkungan, asal kata Jajangkungan yang artinya tinggi jadi jajangkungan yaitu membuat jadi tinggi (Alif, 2003). Di mana mainan yang menggunakan dua bilah bambu yang kemudian disambungkan memakai bilah pendek kearah horizontal untuk pijakan. Ketinggian pijakan bisa buat sesuai dengan kemampuan anak. Permainan ini membutuhkan keseimbangan yang sangat tinggi. Karena pengoperasiannya seperti layaknya orang berjalan. Permainan ini juga disebut permainan orang dewasa karena permainan ini dulunya digunakan untuk transportasi ke Mesjid. Tapi biasanya anak juga menggunakannya tapi sesuai dengan tinggi anak. Dalam permainan egrang ini sering dilombakan seperti lomba lari mulai dari star sampai finish dengan jarak 100-200 meter. Di samping itu juga permainan ini dijadikan permainan saling menjatuhkan dengan menendang kaki - kaki si lawan hal ini menjadi menarik dan siapa yang jatuh itu adalah yang kalah. Di lingkungan anak - anak biasanya yang disebut jago apabila si anak bisa mencapai yang paling tinggi diantara anak - anak lainnya.

\section{2).Gambaran Umum Mengenai Permainan Egrang}

Egrang merupakan permainan tradisional yang menggunakan sepasang bamboo yang memiliki ukuran yang sama dengan kira-kira 1,5 meter kemudian permainannya dilakukan secara berlari atau berjalan. Biasanya anak-anak yang bermain egrang berlari menggunakan garis awal dan berlari ke garis akhir dan yang duluan sampai garis akhir akan menjadi pemenang. Egrang terbuat dari dua batang bambu dengan diameter seukuran lengan orang dewasa yang relatif lurus dan sudah tua dengan panjang masing-masing berkisar 1,5 - 3 meter, salah
Gorga Jurnal Seni Rupa

Volume 08 Nomor 01 Januari-Juni 2019

p-ISSN: 2301-5942 | e-ISSN: 2580-2380

satu pangkal atau ujung bambu (lebih kurang 20 - 30 $\mathrm{cm}$ dari salah satu pangkal bambu) dilubangi untuk memasukan potongan bambu yang berukuran lebar 20 $\mathrm{cm}$ sebagai tempat menginjakan kaki. Ikat atau paku pada bagian potongan bambu dan lobang, pastikan sambungan kuat untuk dinaiki. (Widodo, 2016).

Permainan egrang merupakan permainan ketangkasan dimana permainan ini mengajarkan bagaimana menjaga keseimbangan seperti layaknya berjalan. Biasanya permainan ini dimainkan oleh anak-anak dilapangan besar dengan tujuan supaya bisa berlari sepuasnya dan lebih leluasa pada saat bermainnya. Hal ini permainan egrang adalah permainan adu kecepatan yang pola bermainnya berlari ke salah saatu sisi menuju sisi yang lainnya kemudian kembali ke sisi awal.

\section{3).Teknik Memainkan Egrang}

Permainan Egrang dilakukan oleh muda mudi, umumnya anak laki - laki mulai yang umur 10-25 tahun dan hanya sebagian kecil anak perempuan. Permaianan ini merupakan permainan ketangkasan. Dalam permainan ini kedua bambu dipegang kuat dalam posisi tegak, kemudian salah satu kaki diangkat tepat mengenai bambu/kayu pendek sebagai tempat kaki kemudian kaki yang satunya ikut diangkat. Keseimbangan sangat diperlukan pada bagian ini karena kita harus berusaha tidak jatuh. Pada bambu panjang dijepitkan ibu jari dan jari kaki lainnya, dan apabila sudah seimbang, maka jari menjepit ikut menentukan kekuatan disamping tangan yang memegang. Kemudian langkahkan kaki seperti layaknya orang berjalan.

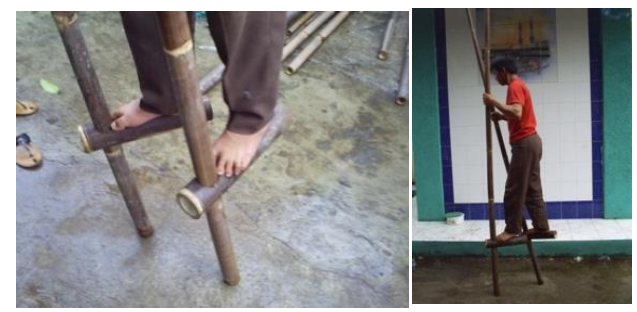

Gambar 2. Teknik Memainkan Egrang (Sumber: Kendall Malik, 2007)

Permainan egrang ini sering dilombakan seperti lomba lari mulai dari star sampai finish dengan jarak 100-200 meter. Di samping itu juga permainan ini dijadikan permainan saling menjatuhkan dengan menendang kaki - kaki si lawan hal ini menjadi menarik dan siapa yang jatuh itu adalah yang kalah. Di lingkungan anak - anak biasanya yang disebut jago apabila si anak bisa mencapai yang paling tinggi diantara anak - anak lainnya. 


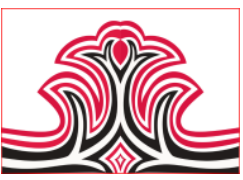

\section{Pembahasan}

Nilai budaya yang terkandung dalam permainan ini adalah kerja keras, keuletan, keseimbangan dan sportivitas. Permainan egrang ini biasanya diperlombakan untuk memeriahkan acara peringatan Hut Kemerdekaan suatu daerah dan negara, seperti di Indonesia biasanya enggrang ini dimaikan waktu acara kemerdekaan atau festival-festival budaya. Di bawah ini merupakan jenis permainan egrang dan makna budaya dari empat negara yang berbeda, meliputi:

\section{1).Permainan Egrang di Indonesia}

Mainan egrang sudah tersebar di mana-mana, namun menggunakan nama yang berbeda - beda. Egrang yang telah dimainkan sejak turun temurun dari zaman nenek moyang, biasanya terbuat dari bahan bambu. Egrang yang dalam bahasa Sunda disebut "jajangkungan" yang diartikan tinggi - tinggian, mainan yang disebut main tinggi - tinggian. Sedangkan di daerah Sulawesi Tengah, egrang dinamakan Tilako yang berarti alat yang dipakai untuk melangkah atau berjalan.

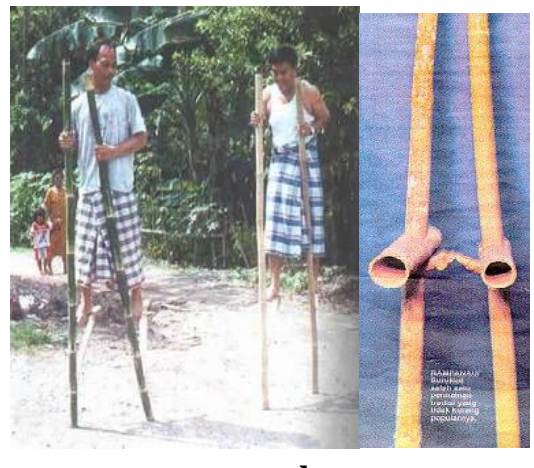

a $\mathbf{b}$

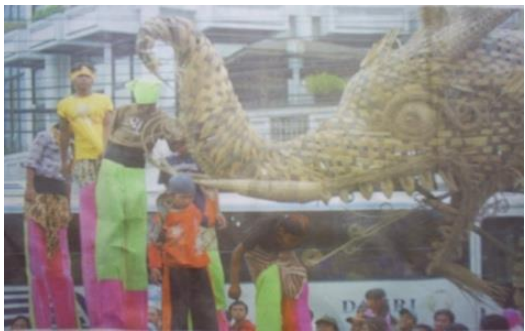

Gambar 3. (a) Egrang dan (b) Tilako, nama egrang dari Sulawesi (c) Egrang tanpa pegangan, pada acara Braga Festival 2006

(Sumber : http//www.infokom-sulteng.go.id/Tilako/diakses pada tanggal 28 Desember 2006 dan Koran Pikiran Rakyat terbit tanggal 28 Desember 2006 )
Gorga Jurnal Seni Rupa

Volume 08 Nomor 01 Januari-Juni 2019

p-ISSN: 2301-5942 | e-ISSN: 2580-2380

Sisi pemaknaan pada mainan ini adalah lambang kedewasaan, ketangkasan dan keberanian. Egrang merupakan alat hiburan dalam bermain bersama teman - teman di perkampungan. Mainan egrang sering diperlombakan, seperti lomba lari dan lomba saling menjatuhkan satu sama lain dengan cara memukulkan kaki - kaki bambu dengan kaki bambu temannya. Di samping itu egrang sering diikut sertakan dalam acara - acara tahunan dan arak - arakan.

\section{2).Permainan Egrang di Belgia}

Selain di Indonesia, egrang juga terdapat di belahan mancanegara. Di Belgia, egrang dijadikan mainan untuk bertarung antar dua kelompok yang saling menjatuhkan. Menurut legenda Belgia, pada abad ke 14 seorang raja yang sangat mulia yaitu John dari Flanders, kemudian menjadi maharaja di negara Namur. Orang terkemuka tersebut memohon kepada masyarakat untuk tidak menggunakan alas kaki, menunggang kuda, dan naik perahu atau kereta. Awalnya orang - orang kota tidak menyukainya dengan sejumlah egrang yang muncul. Setelah dilihat egrang dapat membuat orang kota terhibur dan girang dengan mainan egrang ini. Sejumlah orang kota setuju dengan permohonan tersebut.

Semenjak itu penduduk Namur yang memulai kebiasaan menggunakan egrang. Permainan ini berpindah - pindah sehingga permainan menjadi cepat. Permainan ini membutuhkan 2 kelompok. Yang satu kelompok tinggal di Kota Tua yang disebut "Melans" dan yang kelompok baru disebut Kota Baru yang dipanggil "Avresses". Setiap kelompok mempunyai kapten dan mengunakan warna yang terdapat di egrang, warna kuning dan hitam adalah kota untuk Melans, sedangkan merah dan putih untuk Avresses. Dalam permainan ini diiringi dengan suara drums, dan ke dua kelompok saling bertarung dan saling menduduki atau memperebutkan kota. Untuk menjatuhkan petarung - petarung tersebut mereka menggunakan lengan atau egrang mereka.

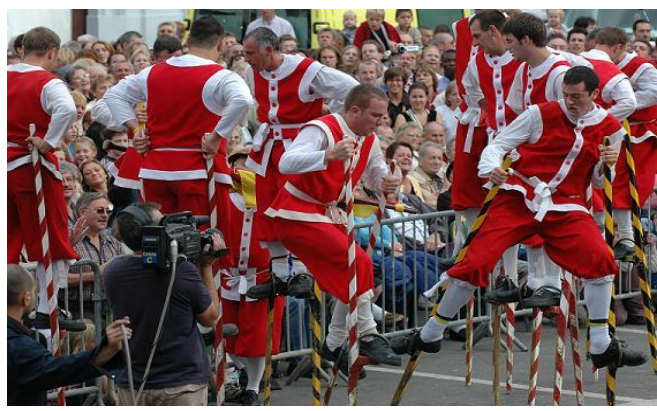

Gambar 4. Pertarungan Egrang di Belgia.

(Sumber : http//www.namur.mht/Tradisional Stilts, namur/diakses pada tanggal 10 Februari 2019)

\section{3).Permainan Egrang di Mexico}

Di Mexico yaitu di Zaachila. Tradisinya menari di atas egrang. Menurut legendanya penduduk Zaachilla membuat perjanjian dengan San Pedro. Ada sebuah gereja yang dibangun di Zaachila, yang disuruh oleh 


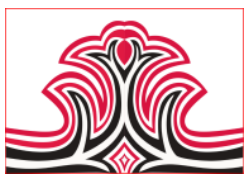

orang suci. Orang suci itu adalah San Pedro, mengatakan dia dikirim oleh Tuhan untuk melindungi desa atau perkampungan tersebut dan dia berkata dia hanya hadir 8 hari sebelum hari ulang tahunnya. Jadi dia menyuruh untuk membentuk pasangan berdiri diatas egrang dan berdansa.

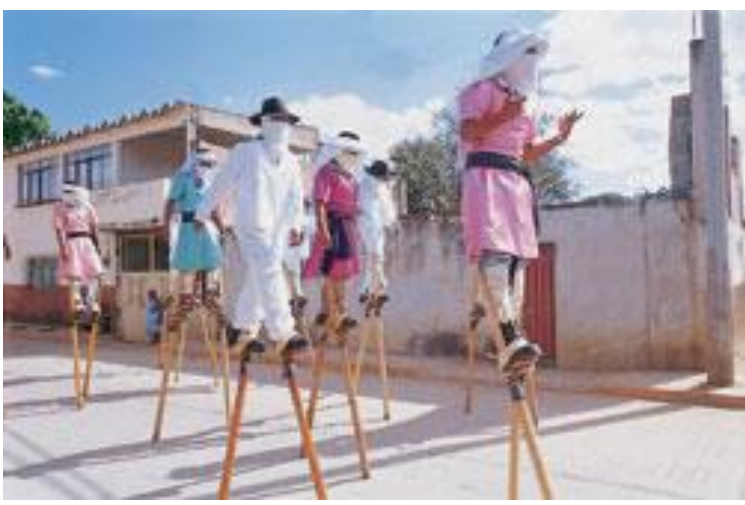

Gambar 5. Kelompok Tradisi Tari Egrang di Mexico. (Sumber: http//www.mexicodesconocido.com/tradisi taro egrang di Mexico/diakses pada tanggal 13 Februari 2019)

\section{4).Permainan Egrang di Nigeria}

Lain halnya pada tradisi egrang yang terdapat di Nigeria. Dalam legenda Tuhan Moko yang berasal dari Kongo dan Nigeria. Dari orang Nuapa. Moko, dalam pengertian tradisionalnya, adalah Tuhan. Dia sangat menjaga kampung atau desanya dan dia sangat tinggi sekali. Dia dapat meramal bahaya dan iblis. Namanya Moko, di menggambarkan laki - laki tinggi di atas egrang dan akan melakukan aksinya yang tidak dapat dijelaskan dari mata manusia. Moko sangat tersentuh dihati orang Africa dan kaum penjajah berjalan dijalan Trinidat dalam perayaan untuk perdamaian, carnaval.

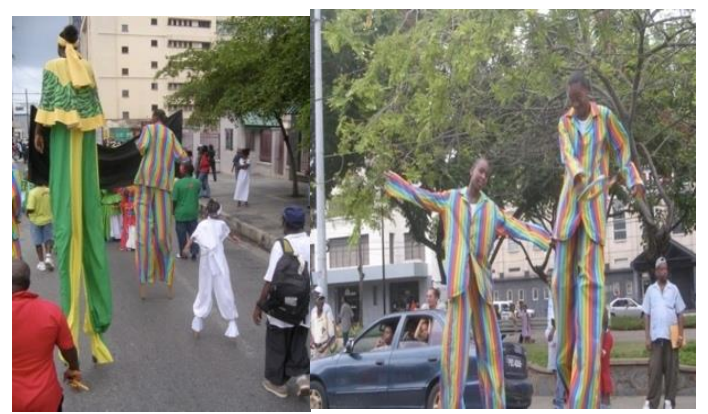

Gambar 6. Tradisi Egrang Moko di Kongo dan Nigeria dalam acara Carnaval.

(Sumber:http//www.traditionalmas.com/Traditional stilt, Moko Jumbies/diakses pada tanggal 26 Maret 2019)

Tradisi-tradisi egrang dari berbagai negara yang didapat memberikan cerita beragam baik di daerahdaerah atau mancanegara. Hal ini menjadi mainan menghibur diri yang menarik dan mainan yang
Gorga Jurnal Seni Rupa

Volume 08 Nomor 01 Januari-Juni 2019

p-ISSN: 2301-5942 | e-ISSN: 2580-2380

berusur ketangkasan. Mainan ini cenderung menarik perhatian karena ketinggiannya yang menbuat atraksiatraksi di arak-arakan pada acara - acara tahunan. Sampai sekarang egrang sudah jarang dan bahkan hampir tak ada lagi. Di lingkungan masyarakat sekarang sudah jarang ditemukan mainan egrang.

\section{KESIMPULA DAN SARAN \\ 1.Kesimpulan}

Berdasarkan hasil analisa perbandingan dari empat negara pada permainan egrang didapat kesimpulan bahwa permainan tradisional memiliki latar belakang nilai budaya, sejarah dan makna disetiap negara. Kemudian permainan tradisional yang terdapat dari empat negara yang dibandingkan bahwa permainan yang dimainkan ada yang berunsur sportifitas, religious, sejarah zaman kerajaan dan termasuk pengaruh legenda dari negara itu sendiri. Permainan tradisional ini telah memberikan pengaruh terhadap lingkungan social dan masyarakat dari negara itu sendiri. Pengaruh yang tercipta itu adalah masyarakat menjadi patuh dan rutin dalam memainkan egrang ini ke dalam suatu acara atau festival yang diselenggarakan oleh daerah atau negara tersebut. Pada acara festival-festifal kesenian, acara rakyat, hari ulang tahun dan hari kemerdekaan suatu negara bahwasanya permainan egrang ini menjadi salah satu permainan yang penting untuk dipertunjukan dalam acara tersebut. Terlihat bahwa permainan egrang ini telah mempersatukan dan menjalin persahabatan antar sesama masyarakat dan lingkungan itu sendiri baik yang dari dalam maupun dari luar.

\section{Saran}

Berkaitan dengan hasil penelitian ini yang belum sempurna maka diharapkan para peneliti untuk dapat melanjutkan penelitian ini secara mendalam yang dikaji dari semua disiplin ilmu (multi disiplin). Kemudian, permainan tradisional sebaiknya kenalkan disekolah-sekolah dan dimainkan di rumah-rumah dekat tempat tinggal mengingat permainan ini sudah jarang dimainkan oleh kalangan anak-anak generasi sekarang. Permainan ini harus dikenalkan kepada anak-anak generasi sekarang karena permainan egrang dapat meningkatkan jiwa sportifitas, kuat, saling kerjasama dan termasuk olah raga ketangkasan. Permainan ini telah memberikan makna dan nilai baik pada diri (si pengguna) maupun bagi lingkungan sosial itu sendiri.

\section{DAFTAR RUJUKAN}

Alif. Z.M. (2003). Perubahan dan Pengembangan Bentuk, Fungsi Dan Material dalam 
Permainan Anak Di Masyarakat Sunda.Tesis. Bandung. Penerbit ITB.

Braga Festival (2006). Diterbitkan oleh Koran Pikiran Rakyat pada tahun 2006.

Departemen Pendidikan dan Kebudayaan. (1998). Permainan Tradisional Indonesia, Jakarta, Direktorat Permuseuman.

Liliweri, Alo. (2004). Komunikasi Antar Budaya, Yogyakarta, Penerbit Mizan.

Namur, Traditional Stilts: Pertarungan Egrang Belgia, diakses pada bulan 10 Februari 2019, dari https://www.namur.mht.

Mexico desconocido, Tradisi Egrang Taro dari Mexico, diakses pada tanggal 13 Februari 2019 , dari https://www.mexicodesconocido.com.

Tradisi Mas Archive, Permainan Tradisional Egrang Masyarakat Negara Nigeria yang Bernama Moko Jumbies, diakses pada tanggal 26 Maret 2019, dari https://www.traditionalmas.com.

Widodo, A.P, Alazim, Udjulawa, D. (2016). Rancang Bangun Aplikasi Permainan Tradisional Egrang Indonesia. Diakses pada tanggal 20 Februari 2019.(online). Di eprints.mdp.ac.id/1874/1/Jurnal.pdf. 